\title{
The Effects of a Relationship Enrichment Educational Program Based on the Theory of Planned Behavior on Infertile Couples
}

\author{
Maryam Alizadeh, ${ }^{1}$ Mohammadreza Miri, ${ }^{2,}$ Bibi Narges Moasheri, ${ }^{2}$ Marzeyeh Ataee, ${ }^{3}$ and Mitra \\ Moodi $^{2}$ \\ ${ }^{1}$ Member of Student Research Committee, Faculty of Health, Birjand University of Medical Sciences, Birjand, IR Iran \\ ${ }^{2}$ Social Determinate of Health Research Center, Birjand University of Medical Sciences, Birjand, IR Iran \\ ${ }^{3}$ Vali-e-Asr Hospital, Birjand University of Medical Sciences, Birjand, IR Iran \\ "Corresponding author: Mohammadreza Miri, Associate Professor of Health Education, Social Determinate of Health Research Center, Department of Public Health, Faculty of \\ Health, Birjand University of Medical Sciences, Birjand, IR Iran. E-mail: miri_moh2516@yahoo.com
}

Received 2015 December 20; Revised 2016 April 5; Accepted 2016 April 20.

\begin{abstract}
Background and Aim: Infertility is associated with physical, financial, psychological, and social stress, and affects all aspects of infertile couples' lives. It is among the most stressful life events and can inflict psychological damage on couples. The present study sought to evaluate the effects of a relationship enrichment educational program, based on the theory of planned behavior, on infertile couples.

Methods: This was a pretest-posttest quasi-experimental study. The study population was all infertile couples, which had referred to the offices of obstetricians in Birjand, Iran. Thirty-two infertile couples were recruited and randomly allocated to either an experimental or a control group. Data were collected at three time points, before, immediately after, and three months after the intervention, using a researcher-made instrument developed based on the constructs of the Theory of Planned Behavior. The study intervention was a relationship enrichment educational program, which was developed based on the theory of planned behavior and implemented in six ninety-minute sessions in three weeks. Education was provided using the lecture method, PowerPoint presentations, and video clips. The SPSS software (v. 16.0) was used to analyze the data through performing independent sample t test and the repeated measures analysis of variance.

Findings: At baseline, there were no significant differences between the groups regarding the participants' demographic characteristics and the mean scores of the constructs of the Theory of Planned Behavior. However, following the study intervention, the scores for attitude, subjective norms, perceived behavioral control, and intention constructs of the theory significantly increased from 79.59 $\pm 13.6,43.7 \pm 9.7,2.5 \pm 1$, and $1.5 \pm 0.6$ to $95.63 \pm 11.4,51.8 \pm 8.1,4.3 \pm 0.7$, and $2.7 \pm 0.5$, respectively $(\mathrm{P}<0.05)$.

Conclusions: The relationship enrichment educational program can significantly improve the scores of the constructs of the Theory of Planned Behavior among infertile couples.
\end{abstract}

Keywords: Relationship Enrichment, Theory of Planned Behavior, Infertile Couples

\section{Introduction}

Infertility is one of the major crises of life, which can cause psychological problems and considerable stress (1). As a serious public concern, infertility can inflict psychological damage on infertile couples and result in mental instability and divorce (2).

Infertility is defined as the inability of a couple to become pregnant despite an entire year of attempts without using any contraception and diagnosis of infertility from a specialist (1-3). The world health organization estimated that around 60 to 80 million couples have infertility throughout the world. Infertility affects almost $10 \%$ to $15 \%$ of couples, who are at the childbearing age. It can also affect the quality of married life, create marital dissatisfaction, reduce intimacy, instill fear over separation, and lead to frustration (4). Infertility is the fourth most stressful life event only after mother's death, father's death, and marital infidelity (5). Beside deprivation from children, infertile couples in traditional societies may experience different personal, familial, social, and financial challenges. Moreover, infertility places people at risk for different psychoemotional problems and strains (2).

In the context of the Iranian culture, parents and significant others play a significant role in couples' lives and, thus, infertility produces more profound effects (6). Due to infertility, most infertile Iranian males and females are stigmatized. Infertility impels couples to go through different arduous therapeutic processes and causes them a wide range of sexual, marital, and health problems, as well as low marital intimacy, feeling of guilt, despair, depression, low self-esteem, and marital dissatisfaction $(7,8)$. It affects couples' interpersonal relationships, decision mak- 
ing ability, and emotional health (8). Studies show that $80 \%$ of infertile couples experience marital dissatisfaction, fragile marital relationships, low libido, anger, or negative emotions (9). Mollaei Nezhad et al. (2009) found that infertility-induced distress caused marital problems and reduced marital satisfaction among females (10). Besides, Agha Mohamadian et al. (2014) also showed that as a stressor, infertility was significantly correlated with irrational beliefs (such as perfectionism) and significantly affected sexual function (11).

Currently, there are numerous methods for improving the quality of married life and training marital relationship skills. One of the methods for improving marital relationships is enrichment (12). Relationship enrichment(RE) is method for improving marital relationships through setting goals for the marriage. Studies showed that RE has positive effects $(12,13)$ and helps people improve their relationships and maintain the quality of their relationships over time. Relationship Enrichment is a skill training model for enhancing marital satisfaction and the stability of a marital relationship. In RE programs, couples learn to accept and sympathize with each other. Nazari et al. (2014) reported the positive effects of psycho-educational approaches on the learning of married life skills (13). Moreover, RE programs were reported to significantly improve marital adaptation (13) and marital relationships (14).

Effectiveness of health education programs greatly depends on the accurate use of educational and behavioral theories and models $(15,16)$. Studies also showed that the most effective educational programs are those that are based on behavior modification theories and models. Thus, the first step in planning an educational program is to select an appropriate health education model (17). The Theory of Planned Behaviors (TPB) is amongst models used mental health education.

Theory of Planned Behaviors is a cognitive-social decision-making model, which provides a useful framework for predicting and explaining health-related behaviors $(16,18)$. Thus, it can provide a useful theoretical framework for predicting infertile couples' behaviors and improving their functioning and satisfaction. It determines the correlations among behaviors, beliefs, attitudes, and intention and introduces intention as the most important predictor of behavior (16-18). Figure 1 shows that the intention to show a given behavior is predicted by the attitude towards that behavior, subjective norms, and perceived behavioral control (15-18).

In the TPB, intention is an individual's decision to perform a behavior while behavior is the way the individual acts. Habit is also the way of reacting in different situations (18), while attitude towards behavior is the degree of ideality of a given behavior (16-18). Moreover, the concept of sub-

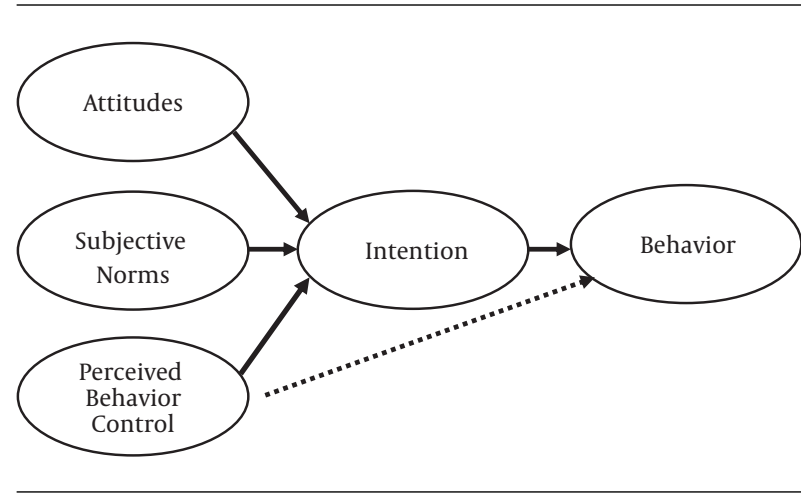

Figure 1. The Theory of Planned Behavior

jective norms points to perceived social pressures (from parents, spouses, or physicians), which may require an individual to perform or avoid performing a behavior $(16,17)$. Finally, perceived behavioral control is the perceived simplicity or difficulty of performing a given behavior $(16,17)$. In other words, it shows the degree to which performing or not performing a behavior is under an individual's control (18). Perceived behavioral control can both directly and indirectly affect behavior $(16,17)$.

The TPB holds that a given behavior can be predicted through measuring behavioral intention. As a main construct of the TPB, behavioral intention shows how much people intend and attempt to perform an action (18). According to Armitage and Arden (2002), TPB is the most comprehensive and most appropriate theory for studying behaviors (19).

Our literature review revealed that no study had been conducted in the area of enriching infertile couples' relationships. Studies in this area can provide health authorities with credible information about existing knowledge gaps, help infertile couples understand the effects of infertility on their lives, and improve their coping abilities. The present study sought to evaluate the effects of a TPB-based RE educational program on infertile couples.

\section{Methods}

This was a pretest-posttest quasi-experimental study. The study population was all infertile couples, who referred to the offices of obstetricians in Birjand, Iran, from 20th of April, 2015 to 20th of April, 2016.

The formula for calculating the required sample size for comparing the two means (Equation 1) revealed that 13 couples were needed for each study group. Nonetheless, due to probable attrition, the required sample size was considered to be 20 couples for each group. Some couples withdrew from the study and 15 and 17 couples remained 
in the experimental and the control groups, respectively. Couples were included if they were unable to become pregnant despite 1 year of attempts and received a diagnosis of infertility from obstetricians. Sampling was done conveniently.

$$
\frac{\left(\left(Z_{1-\frac{\alpha}{2}}+Z_{1-\frac{\beta}{2}}\right)^{2} \times\left(S_{1}^{2}+S_{2}^{2}\right)\right)}{\left(\mu_{1}-\mu_{2}\right)^{2}}
$$

The data collection tool was a researcher-made instrument, which was developed based on the 4 constructs of the TPB. Consequently, the instrument contained 4 main subscales namely attitude (24 items), subjective norms (14 items), intention (3 items), and perceived behavioral control (5 items). The items were scored on a 5-point Likerttype scale from 1 to 5 . In positively- and negatively-worded items of the instrument, the highest possible item score, i.e. 5, was allocated to the "Completely agree" and "Completely disagree" responses, respectively. The content validity of the instrument was confirmed by ten experts in health education and epidemiology, while its reliability was assessed through the test-retest method and the internal consistency assessment, which yielded a Cronbach's alpha of 0.91 .

Primarily, informed consent was obtained from all couples and they were ensured about the confidential management of their data. Then, the intervention was implemented for the couples in the experimental group. The intervention was a TPB-based RE educational program, which was implemented in 6 ninety-minute sessions in 3 weeks ( 2 sessions per week). Table 1 shows the content of each session. Education was provided using the lecture method, PowerPoint presentations, and video clips. Couples in the control group did not receive any type of education. After the intervention, posttest was given to all couples in both groups. During the 3-month follow-up period of the study, couples in the experimental group received pamphlets and short messages pertained to the RE educational program. Finally, the second posttest was given at the end of the follow-up period, i.e. 3 months after the main intervention.

Collected data were entered in the SPSS software (v. 16.0) and analyzed at a significance level of less than 0.05 through running the independent-sample t test and the Repeated Measures Analysis of Variance (RM ANOVA).

\section{Findings}

The participants of the study were 32 infertile couples and their mean age was $30.68 \pm 5.24$. The means of the male and female participants' age were $32.06 \pm 5.02$ and
Table 1. Contents of the Six Sessions of the Theory of Planned Behavior-Based Relationship Enrichment Educational Program

\begin{tabular}{|ll}
\hline Sessions & Contents \\
\hline $\mathbf{1}$ & $\begin{array}{l}\text { Introduction and orientation; pretest; communication skills } \\
\text { (such as speaking and negotiations) as the first RE skill }\end{array}$ \\
\hline $\mathbf{2}$ & $\begin{array}{l}\text { Self-assertiveness (the second RE skill); sympathy (the third RE } \\
\text { skill); and encouragement of couples to help and support each } \\
\text { other during the courses of treatments }\end{array}$ \\
\hline $\mathbf{3}$ & $\begin{array}{l}\text { Problem solving to solve the problem of infertility and resolute } \\
\text { conflicts (the fourth RE skill); evaluation of provided solutions }\end{array}$ \\
\hline $\mathbf{5}$ & $\begin{array}{l}\text { Assessing cognitive errors contributing to marital conflicts such } \\
\text { as labeling and mind reading (the fifth RE skill) }\end{array}$ \\
& $\begin{array}{l}\text { Strategies to live happily, express feelings, be optimistic, and } \\
\text { reduce unreasonable expectations (the sixth skill); promotion of } \\
\text { social interactions (the seventh skill) }\end{array}$ \\
\hline $\mathbf{6}$ & $\begin{array}{l}\text { Legal issues pertaining to adoption; finalization of the program; } \\
\text { giving the posttest; and determining the time of follow-up } \\
\text { assessment }\end{array}$ \\
\hline
\end{tabular}

$29.31 \pm 5.17$, respectively. There were no significant differences between the experimental and the control groups, regarding the demographic characteristics of the participants ( $\mathrm{P}>0.05$; Tables 2 and 3 ).

Table 4 shows that in the experimental group, the means of TPB constructs at the posttest and follow-up measurement time points were significantly greater than the baseline values while in the control group, none of the constructs improved significantly. Moreover, at the posttest and follow-up time points, the differences between the groups regarding the TPB constructs were statistically significant.

The results of the RM ANOVA illustrated the effectiveness of TPB-based RE educational program in improving the scores of the TPB constructs in the experimental group compared with the control group. Although at baseline, there were no significant differences between the groups regarding the constructs, the posttest between-group differences were statistically significant.

\section{Discussion}

This study sought to evaluate the effects of a TPB-based RE educational program on infertile couples. Most previous studies on infertile couples dealt mainly with counseling and couple therapy interventions. In other words, no study had yet been made in this area based on the TPB and, thus, we did not discuss the findings based on TPB.

The study findings revealed significant increases in the score of the attitude construct in the experimental group so much so that the attitude score increased from 79.5 at baseline to 90.1 and 95.6 at the posttest and the follow-up time points. In line with this finding, Sadeghi et al. (2015), 
Table 2. Comparing the Groups Regarding Participants' Age and Length of Infertility

\begin{tabular}{|c|c|c|c|c|c|c|}
\hline \multirow[t]{2}{*}{ Variable } & \multirow[t]{2}{*}{ Group } & \multirow[t]{2}{*}{$\mathbf{N}$} & \multirow{2}{*}{$\begin{array}{c}\text { Mean } \pm \text { Standard } \\
\text { Deviation }\end{array}$} & \multicolumn{3}{|c|}{ The Results of the Independent-Sample T Test } \\
\hline & & & & $\mathbf{t}$ & df & P Value \\
\hline \multirow{2}{*}{ Age } & Experimental & 15 couples & $29.9 \pm 4.7$ & \multirow{2}{*}{-1.08} & \multirow{2}{*}{62} & \multirow{2}{*}{0.28} \\
\hline & Control & 15 couples & $31.3 \pm 5.6$ & & & \\
\hline \multirow{2}{*}{ Length of infertility } & Experimental & 15 couples & $5.7 \pm 4.2$ & \multirow{2}{*}{-1.05} & & \multirow{2}{*}{0.29} \\
\hline & Control & 15 couples & $7.1 \pm 5.9$ & & & \\
\hline
\end{tabular}

Table 3. Comparing the Groups Regarding Participants' Educational Status ${ }^{\mathrm{a}}$

\begin{tabular}{lcc}
\hline Education & \multicolumn{2}{c}{ Groups } \\
\cline { 2 - 3 } & Experimental & Control \\
\hline Below diploma & $9(30)$ & $13(38.2)$ \\
Diploma & $10(33.3)$ & $9(26.5)$ \\
University & $11(36.7)$ & $12(35.3)$ \\
Total & $30(100)$ & $34(100)$ \\
\hline
\end{tabular}

${ }^{\mathrm{a}}$ Values are expressed as No. (\%).

Pakpour et al. (2012), Peyman et al. (2015), and Zhang et al. (2009) also reported the positive effects of TPB on attitude $(16-18,20)$. An explanation for these findings may be the fact that the TPB-based RE skill training program helps couples learn newer and more effective strategies for interpersonal interaction and problem solving. In our TPB-based RE educational program, special attention was paid to improve couples' ability to solve their problems and conflicts, particularly in the areas of infertility. Helping people adopt more positive attitudes towards infertility can improve their interpersonal relationships.

Another component of the TPB is subjective norms. The subjective norms construct points to the perceived social pressure to perform or avoid performing a given behavior. In other words, it identifies whether significant others approve or disapprove the behavior. Receiving support from family members and significant others facilitates behavior modification, particularly among infertile couples. Our findings also revealed a significant increase in the score of subjective norms construct in the experimental group (from 43.7 to 50.1) while the score did not change significantly in the control group. Sadeghi and Khanjani (2015), Zeidi (2012), and Peyman and Roudik (2015) also reported the same findings (16-18). Omondi et al. (2013) suggested that higher pressure placed by significant others (including family members, spouses, treating physicians, and friends) on an individual to perform a healthy behaviors was associated with greater likelihood to perform that behavior (21). This is in agreement with our findings. These findings can be attributed to the fact that significant others' support helps infertile couples accept infertility more readily, improves their sympathy and problemsolving ability, promotes their tolerance towards others' reactions, and minimizes the effects of such reactions on their lives.

Perceived behavioral control is another construct of the TPB. It refers to an individuals' perception of his/her control over performing or not performing a given behavior. Our findings revealed that in the experimental group, the score of this construct significantly increased from 2.5 at baseline to 3.7 and 4.3 at the posttest and the follow-up time points, resulting in a significant betweengroup difference after the study. Zeidi (2012) and Peyman and Roudik (2015) also reported the same findings (17, 18). It seems that educational programs for improving infertile couples' perceived behavioral control can enhance their mental health and psychological well-being, motivate them to continue their lives, promote their sympathy, and improve their problem-solving ability.

As another construct of the TPB, intention is a basic and absolute prerequisite for behavior; the stronger the intention, the greater the likelihood to perform a given behavior. However, the correlation between intention and behavior is not complete. In the present study, the score of the intention construct in the experimental group increased significantly from 1.5 at baseline to, respectively, 2.03 and 2.70 at the posttest and the follow-up time points. The between-group differences regarding the intention scores at both the posttest and the follow-up time points were statistically significant. Zeidi (2012) and Peyman and Roudik (2015) also reported the same findings $(17,18)$. More positive subjective norms and attitudes towards infertility help infertile couples make better decisions about continuing their lives via strategies such as receiving infertility treatments, adopting a baby, or living a happy childfree life. In agreement with our findings, Miri et al. (2016) also reported that their RE program significantly improved infertile couples' marital adaptation and satisfaction (22). 
Table 4. Comparing the Groups Regarding Mean Scores of the Constructs of the Theory of Planned Behavior ${ }^{\mathrm{a}}$

\begin{tabular}{|c|c|c|c|c|c|}
\hline Variables & Groups & Pretest & Posttest & Follow-Up & P Value \\
\hline \multirow{2}{*}{ Attitude } & Experimental & $79.5 \pm 13.6$ & $90.1 \pm 11.4$ & $95.6 \pm 11.1$ & $<0.001$ \\
\hline & Control & $76.9 \pm 13$ & $74 \pm 13.2$ & $75.3 \pm 11.5$ & 0.022 \\
\hline Pvalue & & 0.430 & 0 & 0 & \\
\hline \multirow{2}{*}{ Subjective norms } & Experimental & $43.7 \pm 9.7$ & $50.1 \pm 8.2$ & $51.8 \pm 8.1$ & $<0.001$ \\
\hline & Control & $44.6 \pm 8.1$ & $41.4 \pm 7.8$ & $41.7 \pm 6.8$ & $<0.001$ \\
\hline Pvalue & & 0.674 & 0 & 0 & \\
\hline \multirow{2}{*}{ Perceived behavioral control } & Experimental & $2.53 \pm 1$ & $3.7 \pm 0.8$ & $4.3 \pm 0.7$ & $<0.001$ \\
\hline & Control & $2.8 \pm 1.2$ & $2.6 \pm 1.1$ & $2.5 \pm 0.9$ & 0.056 \\
\hline Pvalue & & 0.277 & 0.001 & 0 & \\
\hline \multirow{2}{*}{ Intention } & Experimental & $1.5 \pm 0.6$ & $2 \pm 0.7$ & $2.7 \pm 0.5$ & $<0.001$ \\
\hline & Control & $1.4 \pm 0.7$ & $1.4 \pm 0.7$ & $1.2 \pm 0.6$ & 0.148 \\
\hline Pvalue & & 0.76 & 0.002 & 0 & \\
\hline
\end{tabular}

${ }^{\mathrm{a}}$ Values are expressed as mean $\pm \mathrm{SD}$

This finding can be attributed to the fact that when couples adopt more positive subjective norms and attitudes towards infertility and attempt to solve this problem, they find greater satisfaction with their lives. Overall, in line with the findings of most previous studies, the findings of the present study indicate that the TPB-based RE educational program has many positive effects on infertile couples' lives.

\subsection{Conclusions}

Education is among the keystones of healthcare services. Thus, given the increasing prevalence of infertility and the negative effects of infertility on married life and couples' health, it is essential to develop and use educational interventions based on educational and behavioral theories and models. The findings of the present study showed that the TPB-based RE skill training program can significantly improve infertility-related attitudes, subjective norms, perceived behavioral control, and behavioral intention. Consequently, whenever infertile people acquire adequate knowledge about infertility and adopt a positive attitude towards it, they can wisely decide about performing the most appropriate behaviors. The TPB can be used in educational programs in order to enrich marital relationships.

\section{Acknowledgments}

This article came from a research project approved by the institutional review board and the ethics committee of
Birjand University of Medical Sciences, Birjand, Iran, with the codes of B.9402 and IR.BUMS.1394.66, respectively. The authors hereby show their gratitude to the research council of Birjand University of Medical Sciences, Birjand, Iran, for funding the study. Moreover, we thank obstetricians in Birjand, particularly Dr. Narges Naseh, the participants of the study, and all people, who supported us during the study.

\section{References}

1. Deircondmoghadam A, Delpesheh A. Prevalence of infertility in systematic review methodology. J Obstetr Gynecol Infertil IJOGI. 2013;16(81):1-7.

2. Jonaidy E, Sadodin SN, Mokhber N, Shakeri MT. Comparing the marital satisfaction in infertile and fertile women referred to the public clinics in Mashhad in 2006-07. Iran J Obstetr Gynecol Infertil. 2009;12(1):7-16.

3. Akhtari E, Bioos S, Sohrabvand F. Infertility in Iranian traditional medicine from hakim mohammad azam khan point of view. Iran JObstet Gynecol Infertil. 2015;18(148):18-23.

4. Sahraian K, Jafarzadeh F, Poursamar SL. The relationship between social support and marital satisfaction in infertile women based on infertility factor.J Urmia Nurs Midwifery Faculty. 2015;12(12):1104-9.

5. Ardekani Z, Akhondi MM, Kamali K, Khalaf Z, Eskandari S, Ghorbani B. Mental health status of patients attending avicenna infertility clinic. J Reprod Infertil. 2010;11(4).

6. Abbasi MH, Ghamarani A, Fatehi ZM. The pathology of iranian infertile couples life. Mil Med. 2009;18(1-2):8-20.

7. Ezzati A, Noori R, Hasani G. Pattern of relationships, social support, coping strategies, and social tag with the symptoms of depression in infertile women in Tehran in 2010. J Obstetr Gynecol Infertil IJOGI. 2013;16(45):20-8.

8. Mazaheri M, Keighobadi F. The way to solve problems and marital adjustment in infertile and fertile couples. J Reprod Infertil. 2001:22-32. 
9. Nooranisadoddin SH, Taghi SM, Naghmeh M. Sexual Satisfaction in Fertile and Infertile Women Attending State Clinics in Mashad. Med J Reprod Infertil. 2009;10(4):269-77.

10. Mollaei Nezhad M, Jaafarpour M, Jahanfar SH. Infertility related strees and marital women who referred to Isfahan infertility treatment clinic. Reprod Infertil. 2009;72(73):8-20.

11. Agha Mohamadian $\mathrm{H}$, Zarezadeh $\mathrm{SH}$, Horofghanad M, Hokmabadi M. To examine the relationship between perfectionism and performance Sexual infertile women. J Obstetr Gynecol Infertil IJOGI. 2014;17(97):9-17.

12. Isanezhad O, Ahmadi SA, Etemadi O. Effectiveness of relationship enhancement on marital quality of couples. Int J Behav Sci. 2010;4(1):916.

13. Nazari A, Taaherirad M, Asadi M. Effect relationship enrichment program on marital adjustment couples. I Counsel Psychother. 2014;3(4):527-40.

14. Marchand JF, Hock E. Avoidance and Attacking Conflict-Resolution Strategies Among Married Couples: Relations to Depressive Symptoms and Marital Satisfaction*. Fam Relat. 2000;49(2):201-6. doi: 10.1111/j.1741-3729.2000.00201.x.

15. Tabatabaie V, Taghdese M, Nakhei N, Balale F. The effect of education based on the theory of planned behavior on physical activity personnel Kerman Health Center. J Babol Univ Med Sci. 2010;12(2):62-9.

16. Sadeghi R, Khanjani N. Impact of educational intervention based on theory of planned behavior (TPB) on the AIDS-preventive behavior among health volunteers. Iran J Health Educ Health Promot 2015;3(1):23-31

17. Zeidi M. The Impact of health education based on theory of planned behavior on the prevention of aids among adolescents. Iran J Nurs. 2012;25(78):1-13.

18. Peyman N, Roudik S. The effect of education based on the theory of planned behavior on caries prevention of permanent teeth in fifth grade students in Khaf City. J Mashad Dent Sch. 2015;39(2):123-36.

19. Armitage CJ, Arden MA. Exploring discontinuity patterns in the transtheoretical model: An application of the theory of planned behaviour. Br J Health Psychol. 2002;7(Pt 1):89-103. doi: 10.1348/135910702169385. [PubMed:14596720].

20. Zhang J, Shi L, Chen D, Wang J, Wang Y. Using the theory of planned behavior to examine effectiveness of an educational intervention on infant feeding in China. Prev Med. 2009;49(6):529-34. doi: 10.1016/j.ypmed.2009.10.002. [PubMed:19850063].

21. Omondi DO, Walingo MK, Mbagaya GM, Othuon LO. Understanding physical activity behavior of type 2 diabetics using the theory of planned behavior and structural equation modeling. Int J Hum Soc Sci. 2010;5:160-7.

22. Miri MR, Alizadeh M, Moasheri N, Ataee M, Moodi M. The effects of relationship enrichment program on compatibility and marital satisfaction of infertile couples. J Health Literacy Res. 2016;1(1):53. 